\title{
Tip Speed Ratio Based MPPT Algorithm and Improved Field Oriented Control for Extracting Optimal Real Power and Independent Reactive Power Control for Grid Connected Doubly Fed Induction Generator
}

\author{
D. V. N. Ananth ${ }^{1}$, G. V. Nagesh Kumar ${ }^{2}$ \\ ${ }^{1}$ Department of EEE, Viswanadha Institute of Technology and Management, Visakhapatnam,531173, India \\ ${ }^{2}$ Department of EEE, GITAM University, Visakhapatnam, 530045, Andhra Pradesh, India
}

\section{Article Info}

Article history:

Received Jan 7, 2016

Revised May 1, 2016

Accepted May 16, 2016

\section{Keyword:}

Doubly fed induction generator

Optimal tip speed ratio

Mmaximum power point

tracking

Real and reactive power control

Grid side converter

Wind energy conversion system

\begin{abstract}
Doubly Fed Induction Generator (DFIG) needs to get adopted to change in wind speeds with sudden change in reactive power or grid terminal voltage as it is required for maintaining synchronism and stability as per modern grid rules. This paper proposes a controller for DFIG converters and optimal tip speed ratio based maximum power point tracking (MPPT) for turbine to maintain equilibrium in rotor speed, generator torque, and stator and rotor voltages and also to meet desired reference real power during the turbulences like sudden change in reactive power or voltage with concurrently changing wind speed. The performance of DFIG is compared when there is change in wind speed only, changes in reactive power and variation in grid voltage along with variation in wind speed.
\end{abstract}

Copyright @ 2016 Institute of Advanced Engineering and Science. All rights reserved.

\section{Corresponding Author:}

G. V. Nagesh Kumar,

Departement of EEE,

GITAM University,

Visakhapatnam, 530045, Andhra Pradesh, India.

Email: drgvnk14@gmail.com

\section{INTRODUCTION}

The wind and solar electric power generation systems are popular renewable energy resources and are getting significance due to retreating of primary fuels and because of eco-friendly nature and is available from few kilo-watt power to megawatt rating. The extractable maximum power from wind depends mostly on the pitch angle control of the wind turbine system and operating rotor at optimal speed for DFIG. The maximum power point tracking (MPPT) of wind turbine generator system is for techno-economic benefits. As per literature, four control techniques are used for extracting maximum real power from wind. The strategies are perturbation and observation $(\mathrm{P} \& \mathrm{O})$ control, tip speed ratio (TSR) control, optimal torque control (OTC) and Power signal feedback (PSF) control [1]-[8] with their description in [9],[10]. The P\&O or hill-climb searching (HCS) method generally requires details on rotor speed and variation of wind turbine power for extracting optimal power. This method does not oblige on characteristic curve of wind turbine or parameters of generator [11],[12]. However, for large-inertia wind turbine systems this method goes out of step with rapid variation in wind speed and produces oscillations near the peak points of maximum power locus point. In TSR method, with variations in wind speed, the wind turbine rotational speed will also varied to achieve the optimal TSR [13],[14]. However, an accurate and continuous wind turbine shaft speed and wind speed measurement is required, which in real time is very difficult. In OTC, the control of generator 
torque is done to meet its optimal value to get maximum value of coefficient of power [15],[16]. This method is slower in performance due to slow calculation of wind speed and retrieving data processes by anemometer.

The performance of DFIG wind energy conversion system is compared with PI, ANN and hybrid PI and ANN in [17]. A comparison is made with power transfer matrix and Direct Power Control (DPC). The authors found that compared to DPC, power transfer matrix is having better control over real power generation, faster control action, stable. The performance of DFIG is studied in [18] with the operation of rotor speed adjusting to sub-synchronous and super-synchronous speed. Also independent control of active and reactive power examined in this paper and found that fuzzy controller is better than conventional PI controller. The fuzzy controller is having faster control action and accurate performance due to faster changing disturbances. A hybrid PI and ANN controller for DFIG is examined in [19] to rapidly changing grid voltage conditions. The authors found that, active and reactive powers are having surges and also rotor and stator parameters got disturbed much with PI and their effects are low with ANN. However when using both Pi and ANN, the effects said above got minimized and hence the authors in [19] conclude that hybrid is better control when grid voltage conditions are high. In [20], authors compared the performance of DFIG during three phase to ground when controlled using PI and fuzzy. It is found that with fuzzy, stator and rotor voltage, current and power waveforms are better and have better stability than a conventional PI controller. Predictive direct power control technique is applied to DFIG system in [21] to have quicker and robust performance to maintain constant DC link voltage with lesser harmonic current and for operation during sub synchronous and super- synchronous speed operation. Drooping characteristics of DFIG is studied in [22] and found that DFIG output power is controlled according to varying wind speed.

In this paper, performance of DFIG was compared and analyzed under situations like, (i) with variation in wind speed alone, (ii) with reactive power variation and (iii) with grid voltage variation for same variation in wind speed. In these cases, variation in tip speed ratio and coefficient of turbine power, effect on real and reactive power flows, voltages and current from stator and rotor, rotor speed and electromagnetic torque are examined. The paper was organized as follows: overview of WECS with wind turbine modeling and pitch angle controller in section II; study of mathematical modelling of DFIG in section III, the section IV deals with RSC architecture and design; section V analyses the performance of DFIG for two cases like effect of variation on i) reactive power demand along with variation in wind speed and ii) grid voltage variation with wind speed. Conclusion was given in Section VI followed by appendix and references.

\section{WIND ENERGY CONVERSION SYSTEM (WECS)}

In this study, the WECS is designed using DFIG connected with the stator connected directly to grid and the rotor via a back-to-back PWM-VSC as shown in Figure 1. The control of the system has been done through the rotor side converter (RSC) and the grid side converter (GSC). The MPPT algorithm has been achieved through controlling the turbine shaft blade angle to optimal tip speed, the RSC controls the rotor to rotate and optimal speed. The GSC maintains the DC-link voltage at the reference value by transferring active power to the grid and controls the exchange of reactive power with the grid.

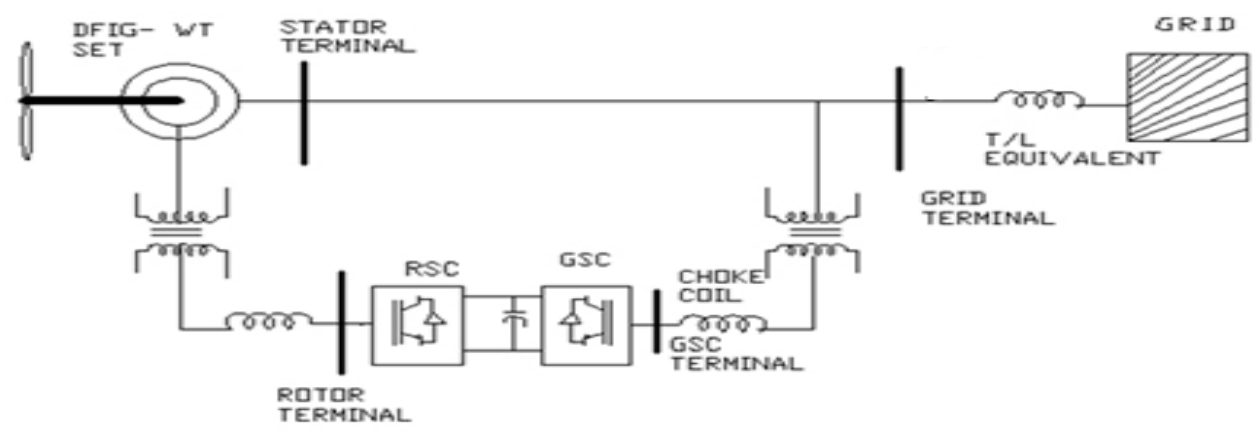

Figure 1. Single line diagram of grid connected DFIG

\subsection{The wind turbine modelling}

The wind turbine is the prime mover which facilitates in converting kinetic energy of wind into mechanical energy which further converted into electrical energy. From basic theory of wind energy conversion, the output mechanical power from turbine is given by 


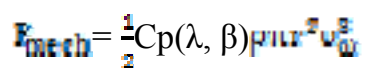

Where ${ }_{\mathrm{men}}^{\mathrm{m}}$ is the mechanical power output from wind turbine, $\mathrm{Cp}$ is coefficient of wind power as a function of pitch angle $(\beta)$ and tip speed ratio $(\lambda) \rho$ is specific density of air, $r$ is radius of wind turbine blade, $\nu_{\omega}$ is wind speed.

$$
\operatorname{Cp}(\lambda, \beta)=0.5176\left(\frac{116}{\Sigma_{1}}-0.4 \beta-5\right) \mathrm{e}^{-21 / \lambda_{1}}+0.0068 \lambda
$$

The tip sped ratio is a relation between turbine speed $\left(\omega_{t}\right)$ radius of turbine blades and wind speed and tip speed ratio at particular angle ' $i$ ' is given the relation as shown below

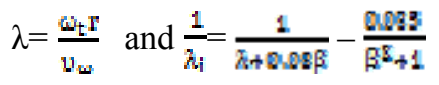

the output power at nominal wind speed is given by the below equation

$$
v_{\mathrm{n}}=\sqrt{\frac{2 \mathrm{~g} p h}{\pi \mathrm{r}^{5} \mathrm{v}_{\mathrm{gmax}}}}
$$

Where Psh is the turbine shaft power and Cp max is maximum mechanical power coefficient. The maximum power from wind turbine can be extracted by using the equation

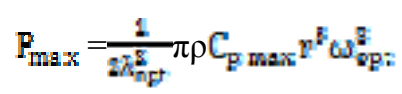

\subsection{Pitch angle controller}

The wind turbine blade angles are controlled by using servo mechanism to maximize turbine output mechanical power during steady state and to protect the turbine during high wind speeds.

This control mechanism is known as pitch angle controller. When wind speed is at cut-in speed, the blade pitch angle is set to produce optimal power, at rated wind speed; it is set to produce rated output power from generator. At higher wind speeds, this angle increases and makes the turbine to protect from overspeeding. The pitch angle controller circuit is as shown in Figure 2a.

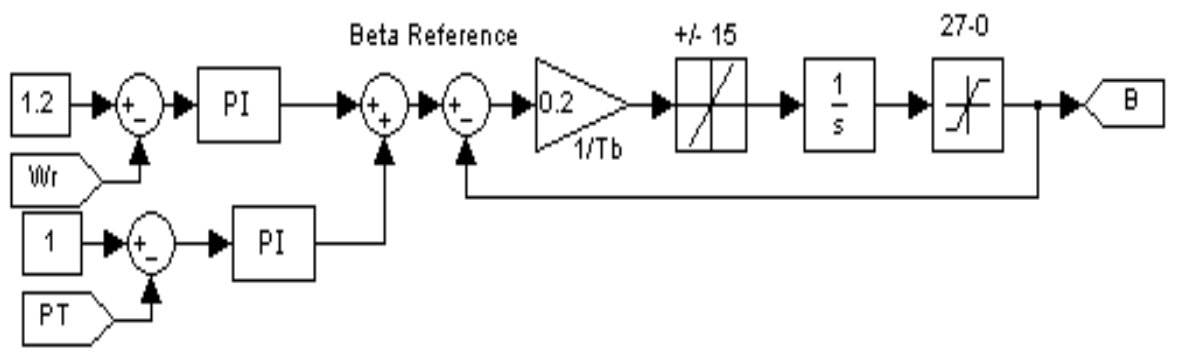

Figure 2a. Pitch angle controller design for wind turbine 


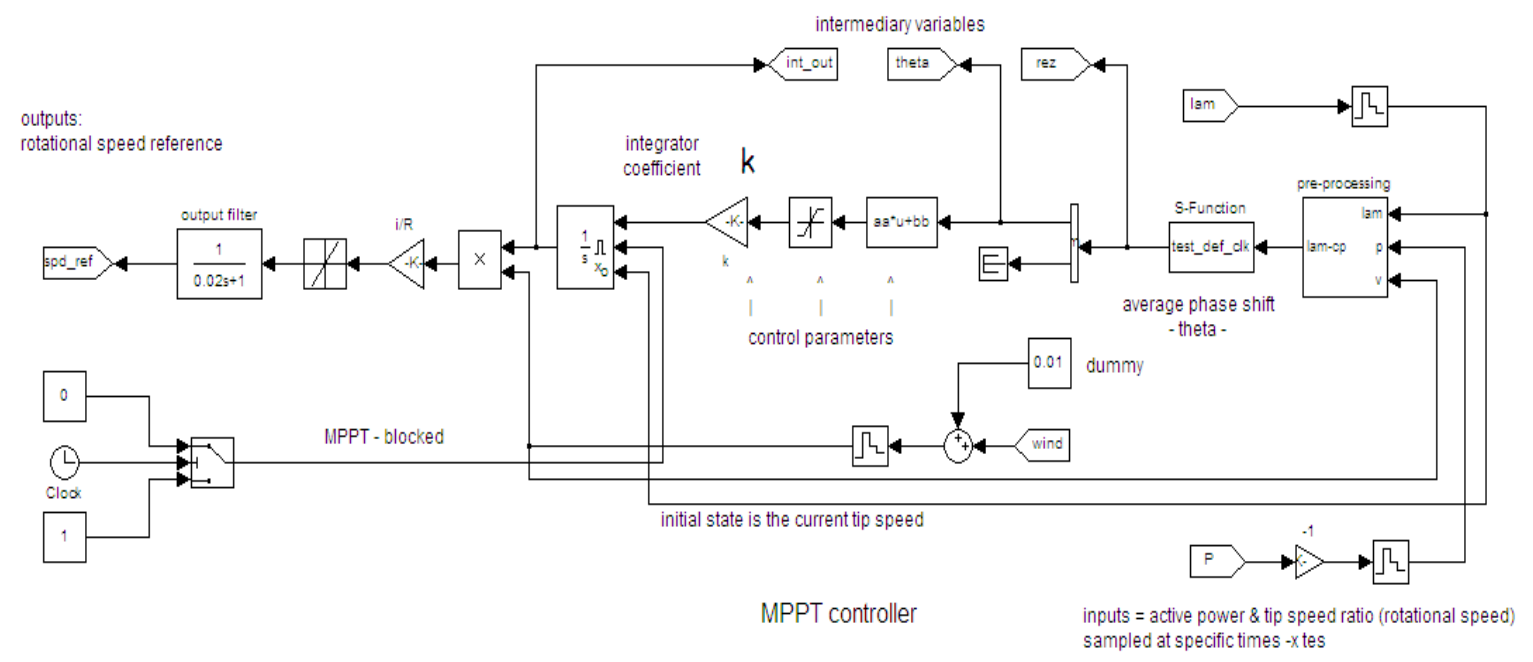

Figure $2 \mathrm{~b}$. MPPT algorithm for wind turbine to develop optimal rotor speed estimation

In this system reference generator speed is $W_{\mathrm{I}}^{\text {ref }}=1.2 \mathrm{pu}$ and actual speed of the generator is Wr. In the similar way, the difference in reference $\left(\mathrm{P}^{*}=1\right)$ and actual power outputs from turbine (PT) is controlled by PI controller. Both the outputs from PI controller are designed to get reference pitch angle controller ( $\beta$ ref). The closed loop control of pitch angle is obtained as shown in Figure 2a. The optimal speed estimation (spd_ref or WR) is shown in Figure 2b. Using Tip Speed Ratio (TSR), wind speed, Coefficient of Power (CP) and mechanical power output from turbine are used as main inputs to generate reference rotor speed. The control scheme is useful to extract maximum mechanical power, thereby more mechanical torque (Tm) by using the optimal tip speed ratio based MPPT algorithm.

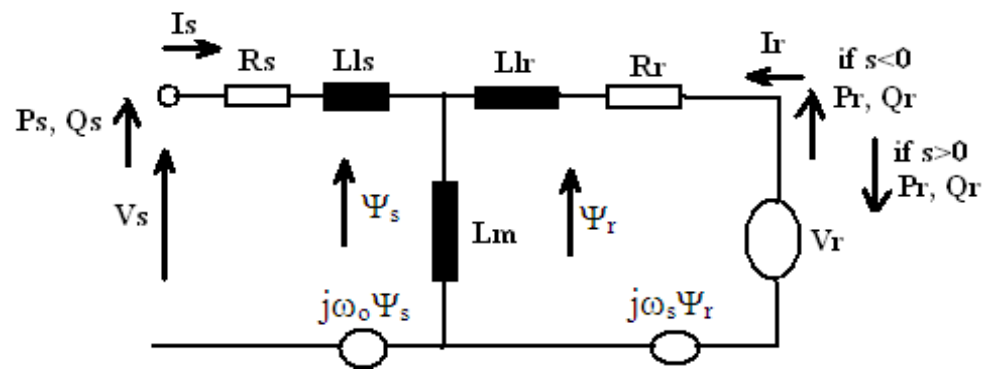

Figure 3. Equivalent circuit of DFIG in rotating reference frame at speed $\omega$

\subsection{Mathematical modeling of DFIG}

The equivalent circuit of DFIG in rotating reference frame at an arbitrary reference speed of $\omega$ is shown in Figure 3. The stator direct and quadrature axis (dq) voltages of DFIG can be written as

$$
\begin{aligned}
& V_{s d}=R_{g} I_{s d}-\omega_{g} \psi_{s q}+\frac{d \psi_{s i}}{d t} \\
& V_{g q}=R_{g} I_{s q}+\omega_{g} \psi_{s d}+\frac{d \psi_{s q}}{d t}
\end{aligned}
$$

The rotor direct and quadrature axis are derives as

$$
\begin{aligned}
& V_{\mathrm{rd}}=\mathbb{R}_{\mathrm{r}} \mathrm{I}_{\mathrm{rd}}-\left(\omega_{\mathrm{g}}-\omega_{\mathrm{r}}\right) \psi_{\mathrm{rq}}+\frac{d \psi_{\mathrm{rgd}}}{\mathrm{dt}} \\
& V_{\mathrm{rq}}=\mathbb{R}_{\mathrm{r}} \mathrm{I}_{\mathrm{rq}}+\left(\omega_{\mathrm{g}}-\omega_{\mathrm{r}}\right) \psi_{\mathrm{rd}}+\frac{\mathrm{d} \psi_{\mathrm{rg}}}{d \mathrm{t}}
\end{aligned}
$$


The difference between stator speed $\left(\omega_{2}\right)$ and rotor speed $\left(\omega_{\mathrm{N}}\right)$ is known as slip speed $\left(\omega_{0}\right)$. For motoring action, this difference is less than zero and for generating, the slip speed is negative. The stator and rotor flux linkages in axis frame are given below

$$
\begin{aligned}
& \psi_{\text {gd }}=\mathbf{L}_{\mathrm{lg}} \mathbf{J}_{\mathrm{gd}}+\mathbf{L}_{\mathrm{rw}} \mathbf{J}_{\mathrm{rd}} \\
& \text { or } \psi_{\mathrm{gd}}=\mathbb{I}_{\mathrm{m}} \mathrm{J}_{\mathrm{sm}} \\
& \Psi_{\text {gq }}=\mathbf{L}_{\mathrm{ls}} \mathbf{I}_{\text {งq }}+\mathbf{L}_{\mathrm{w}} \mathbf{I}_{\text {เи }} \\
& \Psi_{\mathrm{rd}}=\mathbf{L}_{\mathrm{lr}} \mathbf{I}_{\mathrm{rd}}+\mathbf{L}_{\mathrm{m}} \mathbf{I}_{\mathrm{gd}} \\
& \psi_{\mathrm{rq}}=\mathbf{I}_{\mathrm{lr}} \mathbf{I}_{\mathrm{rq}}+\mathbf{I}_{\mathrm{m}} \mathbf{J}_{\mathrm{sq}}
\end{aligned}
$$

The stator real power in terms of two axis voltage and current is

$$
\mathrm{F}_{\mathrm{3}}=\frac{7}{2}\left(\mathrm{~V}_{\mathrm{gd}} \mathrm{I}_{\mathrm{gd}}+\mathrm{V}_{\mathrm{sq}} \mathrm{I}_{\mathrm{sq}}\right)
$$

The rotor real power in terms of two axis voltage and current is

$$
\mathrm{P}_{\mathrm{v}}=\frac{3}{2}\left(\mathrm{~V}_{\mathrm{ud}} \mathrm{I}_{\mathrm{rd}}+\mathrm{V}_{\mathrm{rq}} \mathrm{I}_{\mathrm{rq}}\right)
$$

The stator reactive power in terms of two axis voltage and current is

$$
\mathrm{Q}_{\mathrm{g}}=\frac{3}{2}\left(\mathrm{~V}_{\mathrm{gq}} \mathrm{I}_{\mathrm{gd}}-\mathrm{V}_{\mathrm{gd}} \mathrm{I}_{\mathrm{sq}}\right)
$$

The rotor reactive power in terms of two axis voltage and current is

$$
\mathrm{Q}_{\mathrm{r}}=\frac{\mathrm{a}}{2}\left(\mathrm{~F}_{\mathrm{rq}} \mathrm{I}_{\mathrm{rd}}-\mathrm{F}_{\mathrm{rd}} \mathrm{I}_{\mathrm{re}}\right)
$$

The quadrature and direct axis rotor current in terms of stator parameters can be written as

$$
\begin{aligned}
& \mathrm{I}_{\mathrm{sq}}=\frac{\mathrm{P}_{\mathrm{g}}}{\left|\mathrm{V}_{\mathrm{g}}\right|}=\frac{-\mathrm{L}_{\mathrm{l}} \mathrm{s}}{\mathrm{L}_{\mathrm{m}}} \mathrm{I}_{\mathrm{sq}} \\
& \mathrm{I}_{\mathrm{ad}}=\frac{\mathrm{g}_{\mathrm{m}}}{\left|\mathrm{V}_{\mathrm{g}}\right|}+\frac{\left|\mathrm{V}_{\mathrm{g}}\right|}{\mathrm{G}_{\mathrm{g}} \mathrm{L}_{\mathrm{m}}}
\end{aligned}
$$

The output electromagnetic torque is given by the equation

$$
T_{\mathrm{z}}=\frac{3}{2} \beta \mathrm{I}_{\mathrm{m}}\left(\mathrm{T}_{\mathrm{sq}} \mathrm{T}_{\mathrm{rd}}-\mathrm{T}_{\mathrm{sd}} \mathrm{I}_{\mathrm{rq}}\right)
$$

The mechanical torque output from the turbine in terms of mechanical power and rotor speed is

$$
\mathrm{T}_{\mathrm{m}}=\frac{\mathrm{P}_{\mathrm{ma}=\mathrm{h}}}{\omega_{\mathrm{r}}}
$$

\section{ROTOR SIDE CONTROLLER (RSC) AND GRID SIDE CONTROLLER (GSC) \\ ARCHITECTURE AND DESIGN}

The control circuit for grid side controller (GSC) is shown in Figure 4a. The rotor side converter (RSC) in Figure $4 \mathrm{~b}$ is used to control the speed of rotor and also helps in maintaining desired grid voltage as demanded. The GSC and RSC have four control loops each, later has one speed control loop, other is reactive power and last two are direct and quadrature axis current control loops. The speed and reactive power control loops are called outer control loop and direct and quadrature axis control loops are called inner control loops. The difference between reference speed of generator and actual speed of generator is said to be rotor speed error. Speed error is minimized and maintained nearly at zero value by using speed controller loop which is a PI controller. The output from speed controller is multiplied with stator flux (Fs) and ratio of stator and rotor (Ls and Lr) inductances to get reference quadrature current (Iqr) for rotor. The error in reference and actual

Tip Speed Ratio Based MPPT Algorithm and Improved Field Oriented Control for .... (D. V. N. Ananth) 
reactive power give reference direct axis current (Iqr). The difference between these reference and actual two axis currents is controlled by tuned PI controller to get respective direct and quadrature axis voltages.

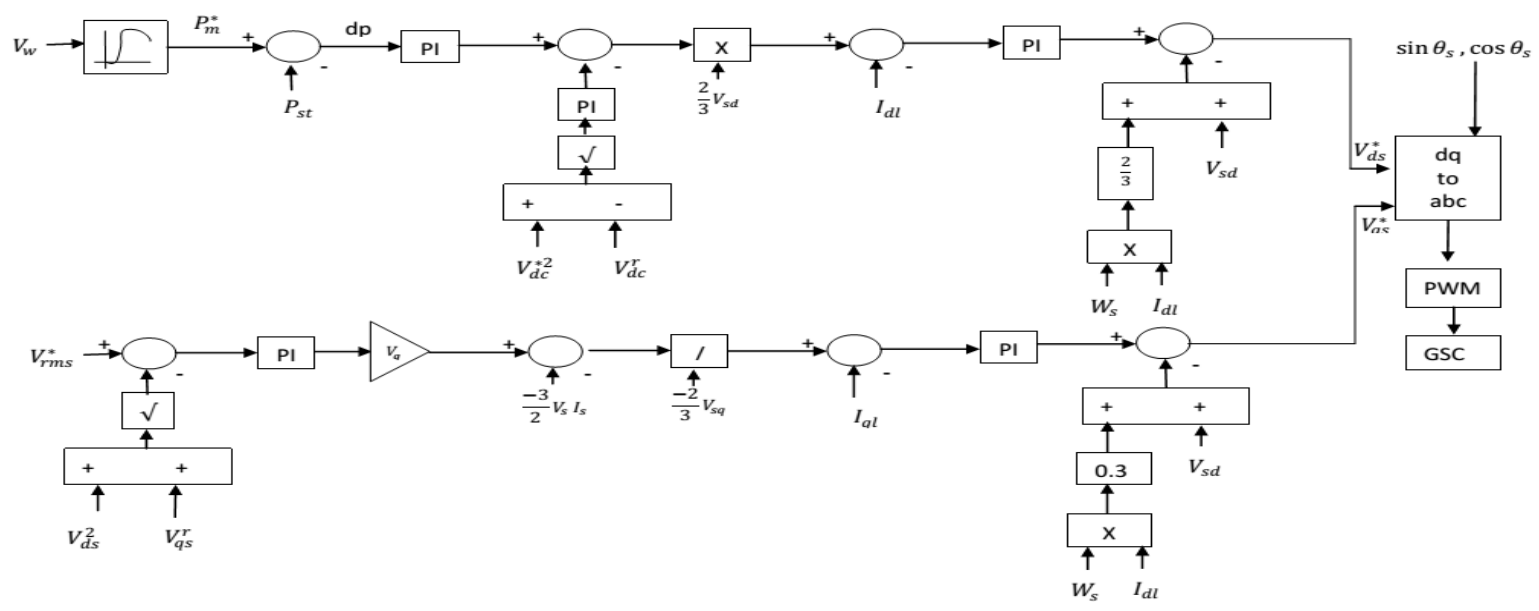

Figure 4a. Grid side controller for DFIG

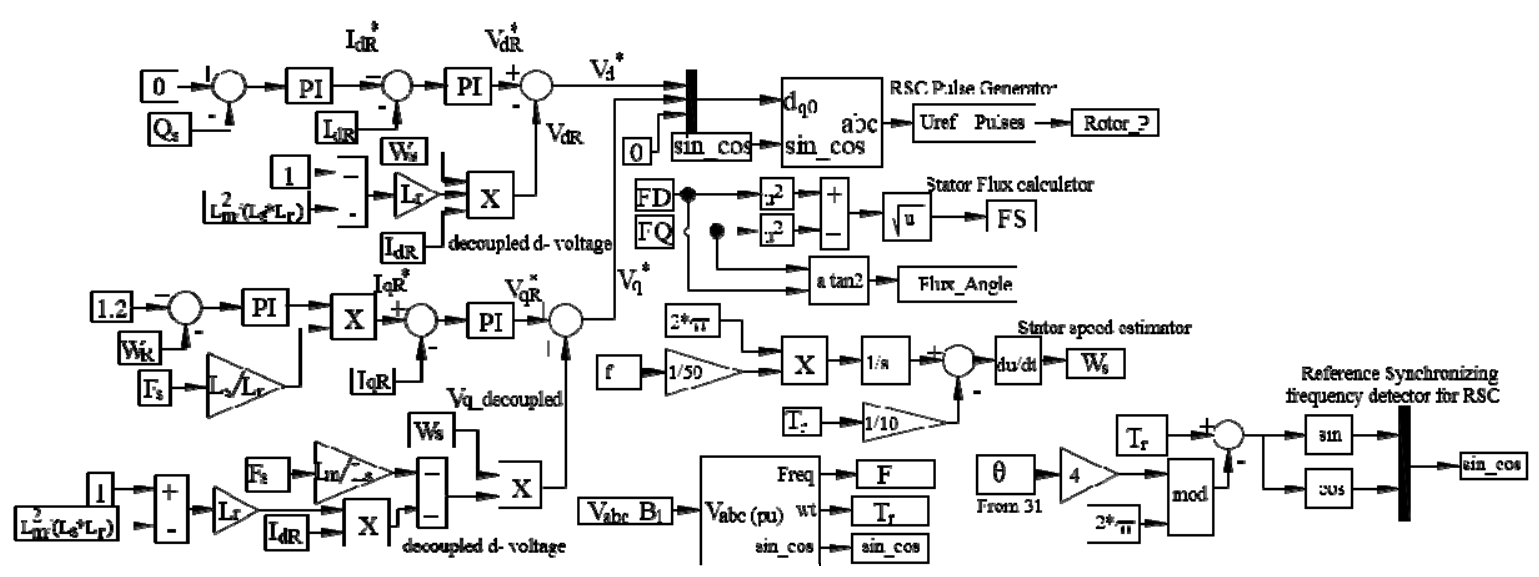

Figure 4b. Rotor side controller for DFIG

For given wind speed, reference or control power from turbine is estimated using lookup table. From equation (15), stator real power (Pstator) is calculated and the error in powers is difference between these two powers $(\mathrm{dP})$ which is to be maintained near zero by PI controller. The output from PI controller is multiplied with real power constant $(\mathrm{Kp})$ gives actual controllable power after disturbance. The difference in square of reference voltage across capacitor dc link $\left(\mathrm{Vdc}^{*}\right)$ and square of actual dc link voltage (Vdc) is controlled using PI controller to get reference controllable real power. The error in the reference and actual controllable power is divided by using $2 / 3 \mathrm{Vsd}$ to get direct axis (d-axis) reference current near grid terminal (Igdref). Difference in Igdref and actual d-axis grid current is controlled by PI controller to get d-axis voltage.

Similarly from stator RMS voltage (Vs) or reference reactive power, actual stator voltage or reactive power is subtracted by PI controller and multiplied with appropriate reactive power constant (Kq) to get actual reference reactive power compensating parameter. From equation (17), actual reactive power is calculated and the difference in this and actual compensating reactive power and when divided by $2 / 3 \mathrm{Vsq}$, we get quadrature axis (q-axis) reference current (Iqref). When the difference in Iqref and stator actual q-axis current (Iq) is controlled by PI controller, reference q-axis voltage is obtained. To improve transient response and to control steady state error, decoupled q-axis voltage has to be added as shown in Figure 4a. Finally both $\mathrm{d}$ and $\mathrm{q}$ axis voltage parameters so obtained are converted to three axis abc parameters by using inverse Park's transformation and reference voltage is given to scalar PWM controller to get pulses for grid side controller. 
The general form of speed regulation is given by

$$
\begin{aligned}
\mathrm{T}_{\mathrm{e}} & =\mathrm{J} \frac{\mathrm{d} \mathrm{w}_{\mathrm{r}}}{\mathrm{dt}}+\mathrm{B} \omega_{\mathrm{r}}+\mathrm{T}_{\mathrm{l}} \\
& =(\mathrm{J} \mathrm{S}+\mathrm{B}) \omega_{\mathrm{r}}+\mathrm{T}_{\mathrm{l}}
\end{aligned}
$$

Where $T_{t}$ Is electromaguetls torque, $J$ is moment of inertia and $B$ is friction coefficient, $\mathbf{T}_{l}$ is considered to be disturbance. Multiplying both sides with $\omega_{\text {error }}$, we get the equation as

$$
\mathrm{T}_{\mathrm{f}} \omega_{\mathrm{error}}=(\mathrm{JS}+\mathrm{B}) \omega_{\mathrm{r}} \omega_{\text {error }}+\mathrm{T}_{\mathrm{l}} \omega_{\text {error }}
$$
becomes.

Considering $\omega_{r}$ constant and change in speed error is $\omega_{\text {erro }}$ is control variable, the above equation

$$
\mathbf{P}_{\mathrm{g}}^{*}=\left(\mathbf{K}_{\text {in }} \mathrm{S}+\mathbf{K}_{\mathrm{pn}}\right) \omega_{\text {trm }}+\mathbf{P}_{]}
$$

As product of torque and speed is power, we will be getting stator reference power and disturbance power as shown below.

$$
\mathrm{P}_{\mathrm{s}}^{\mathrm{s}}-\mathrm{P}_{\mathrm{L}}^{\mathrm{s}}=\left(\mathrm{K}_{\mathrm{in}} \mathrm{S}+\mathrm{K}_{\mathrm{pn}}\right) \omega_{\text {error }}
$$

Where, $\mathrm{K}_{\text {in }}=\mathrm{J}^{*} \omega_{\mathrm{r}}$ and $\mathrm{R}_{\mathrm{pn}}=\mathrm{B} \boldsymbol{\omega}_{\mathrm{r}}$

Finally direct axis reference voltage can be written by using equation (26) and from Fig. $5 \mathrm{~b}$ is

$$
\begin{aligned}
& V_{\mathrm{rd}}^{s}=-\left(\omega_{\mathrm{errw}}\right)\left(\mathrm{K}_{\mathrm{pn}}+\frac{K_{\mathrm{in}}}{\mathrm{a}}\right)+\left(\mathbf{P}_{\mathrm{a}}\right)\left(\mathrm{K}_{\mathrm{pt}}+\frac{K_{\mathrm{it}}}{\mathrm{a}}\right) \\
& V_{\mathrm{rq}}=Q_{\mathrm{error}}\left(\mathrm{K}_{\mathrm{pQ}}+\frac{K_{\mathrm{ig}}}{\mathrm{a}}\right)
\end{aligned}
$$

The rotating direct and quadrature reference voltages of rotor are converted into stationary abc frame parameters by using inverse parks transformation. Slip frequency is used to generate sinusoidal and cosine parameters for inverse parks transformation.

\section{RESULT ANALYSIS: CASE STUDIES}

The dynamic performance of the DFIG system is investigated under two different cases and the rating specifications for DFIG and wind turbine parameters is given in appendix. The wind speed change in these two cases in meters per seconds as 8, 15, 20 and 10 at 15,25 and 35 seconds. The reactive power and voltage value change in individual two cases with change in time is from $-0.6 \mathrm{pu}$ at 12 seconds to $0 \mathrm{pu}$ change at 20 seconds. It was further changed from $0 \mathrm{pu}$ to $+0.6 \mathrm{pu}$ magnitude at 30 seconds. Due to addition of large furnace or induction motor or non linear type load, leading reactive power greater than 0 pu is required, while for light load lagging reactive power is required $(<0 \mathrm{pu})$. Hence DFIG will become better generator source if it can supply any desired reactive power effectively. The change in grid terminal voltage takes place when suddenly switching on or off large loads or due to small faults near PCC.

The changes in tip- speed ration and power coefficient $\mathrm{Cp}$ both reactive power and wind speed variation in Figure 5a (i) and variation with grid terminal voltage and wind speed both is shown in Figure 5a (ii). When wind speed is at $8 \mathrm{~m} / \mathrm{s}$, tip speed ratio (TSR) is high near 4.8 degrees and slowly decreases to 2.60 at $15 \mathrm{~s}$ when speed increases to $15 \mathrm{~m} / \mathrm{s}$, further increased to $1.9 \mathrm{o}$ at $25 \mathrm{~s}$ when speed of wind is $20 \mathrm{~m} / \mathrm{s}$ and decreased to $3.9 \mathrm{o}$ when wind speed decreased to $10 \mathrm{~m} / \mathrm{s}$ at $35 \mathrm{~s}$. In the similar way, Cp is also changing from 3.25 to 1.7 at $15 \mathrm{~s}$, and further decreased to 1.25 at $25 \mathrm{~s}$, and then increased to 2.55 at 35 seconds with wind speed variation from 8 to 15 and then to 20 , and $10 \mathrm{~m} / \mathrm{s}$. The variation in TSR and Cp with change in reactive power is independent and has no effect as shown in Figure 5a (ii). However, with change in grid terminal voltage, a very small change in TSR and Cp can be observed. It is due to the fact that the TSR and $\mathrm{Cp}$ depends on parameters as described by equations 1 to 5 and is independent on voltage and reactive power.

The reference mechanical turbine torque and generator torque with magnitudes overlapping and variation of rotor speed for two cases comparison is shown in Figure $5 \mathrm{~b}$. With increase in wind speed, torque is increasing and vice-versa. Till time up to 15 seconds, wind speed is at low value of $8 \mathrm{~m} / \mathrm{s}$, so torque is at $0.2 \mathrm{pu}$ and increased to $-0.5 \mathrm{pu}$ at $15 \mathrm{~s}$ with increase in wind speed to $15 \mathrm{~m} / \mathrm{s}$. The torque further increased to $0.9 \mathrm{pu}$ when wind speed is $20 \mathrm{~m} / \mathrm{s}$ and decreased to $-0.28 \mathrm{pu}$ when speed decreased to $10 \mathrm{~m} / \mathrm{s}$. there are small

Tip Speed Ratio Based MPPT Algorithm and Improved Field Oriented Control for .... (D. V. N. Ananth) 
surges in torque waveform because of sudden change in wind speed. With the change in wind speed, rotor speed is also varying but is maintained nearly at constant value of $1.3 \mathrm{pu}$ RPM.

The changes in torque has effect with change in reactive power as in Fig. $5 b$ (i) and further more surges been observed when grid voltage disturbance occurred as in Figure $5 \mathrm{~b}$ (ii) is taking place. When reactive power is lagging at $-0.6 \mathrm{pu}$, there is a small surge in torque at 20 seconds. Generator speed is also low at $1.27 \mathrm{pu}$ at $-0.6 \mathrm{pu}$ reactive power, while at $0 \mathrm{pu}$ reactive power, it is $1.32 \mathrm{pu}$ speed. But rotor speed increased to $1.4 \mathrm{pu}$ speed at low terminal grid voltage of $0.8 \mathrm{pu}$. When, reactive power changes to $0 \mathrm{pu}$ from $-0.6 \mathrm{pu}$, rotor speed increase from $1.3 \mathrm{pu}$ to $1.27 \mathrm{pu}$ and grid terminal voltage changes to $1 \mathrm{pu}$ from $0.8 \mathrm{pu}$ between 20 to 30 seconds. Speed further increased to $1.35 \mathrm{pu}$ with leading reactive power of $+0.6 \mathrm{pu}$ and decreased when grid voltage increase from $1 \mathrm{pu}$ to $1.2 \mathrm{pu}$. Therefore rotor speed increases if reactive power changes from lagging (ve) to leading (+ve) and rotor speed decreases with increase in grid terminal voltage beyond $1 \mathrm{pu}$ value in rms. The surges in torque will be observed very high when terminal grid voltage changes is due to the fact of change in mechanical power is not that faster in comparison with electrical power change.

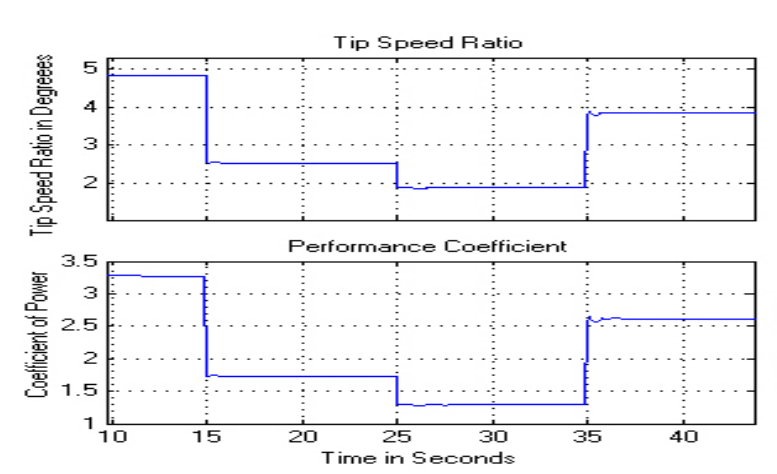

a (i)

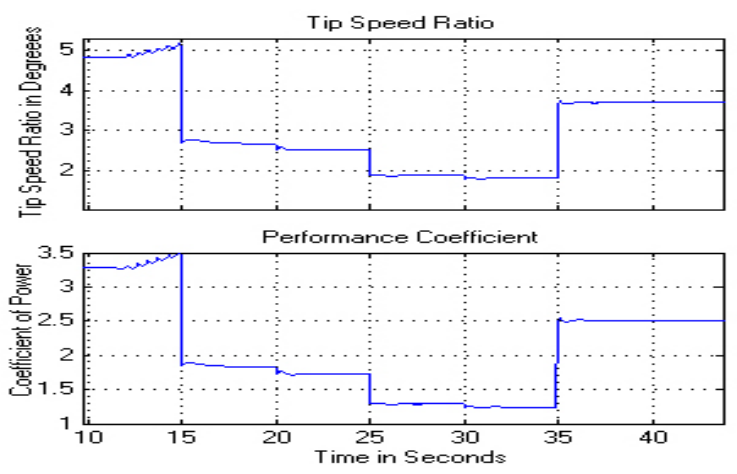

a (ii)

Figure 5a. Tip speed ratio and Coefficient of power $\mathrm{Cp}$ for (i) reactive power change \& wind speed variation, (ii) both grid voltage \& wind speed changes

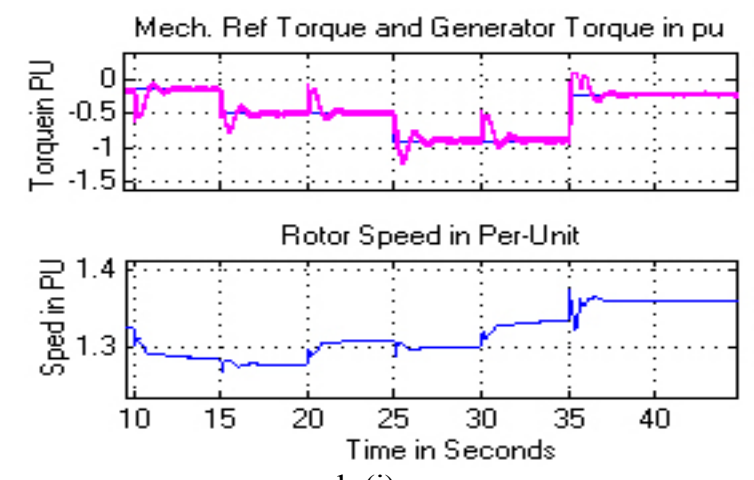

b (i)
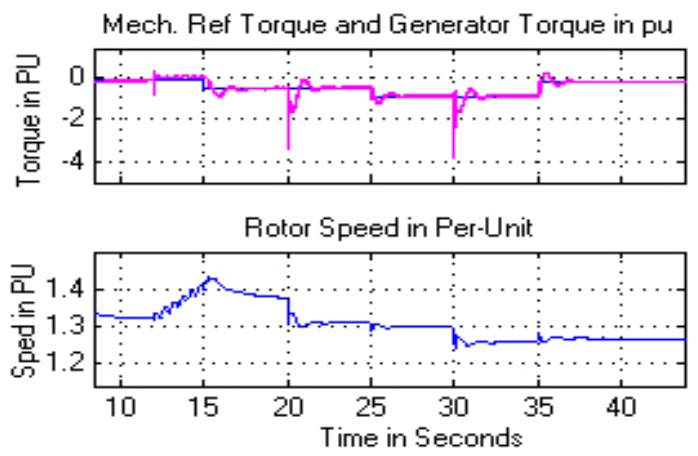

b (ii)

Figure 5b. Reference and actual generator torque and rotor speed variation with time for (i) reactive power change \& wind speed variation, (ii) both grid voltage \& wind speed changes

From Figure 5c (i), there is an increase in current from $0.18 \mathrm{pu}$ to $0.5 \mathrm{pu}$ at 15 seconds with increase in wind speed from 8 to $15 \mathrm{~m} / \mathrm{s}$ and further increased to $0.9 \mathrm{pu}$ amps when speed increased to $20 \mathrm{~m} / \mathrm{s}$ and decreased to $0.3 \mathrm{pu}$ amps when speed of wind is $10 \mathrm{~m} / \mathrm{s}$. When reactive power (Q) change from $0 \mathrm{pu}$ to $-0.6 \mathrm{pu}$, current increased from $0.15 \mathrm{pu} 0.5 \mathrm{pu}$ amps and decreased to $0.5 \mathrm{pu}$ amps when Q changes from $-0.6 \mathrm{pu}$ to $0 \mathrm{pu}$ and increased to $1 \mathrm{pu}$ amps when speed of wind is $20 \mathrm{~m} / \mathrm{s}$ and reactive power is $0.6 \mathrm{pu}$. 


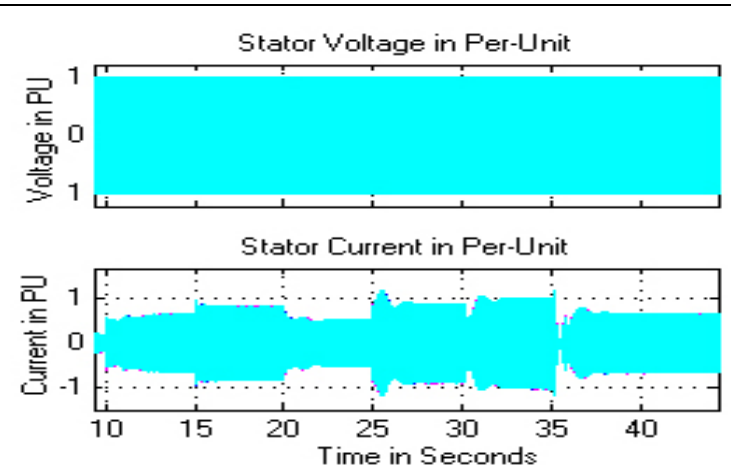

c (i)

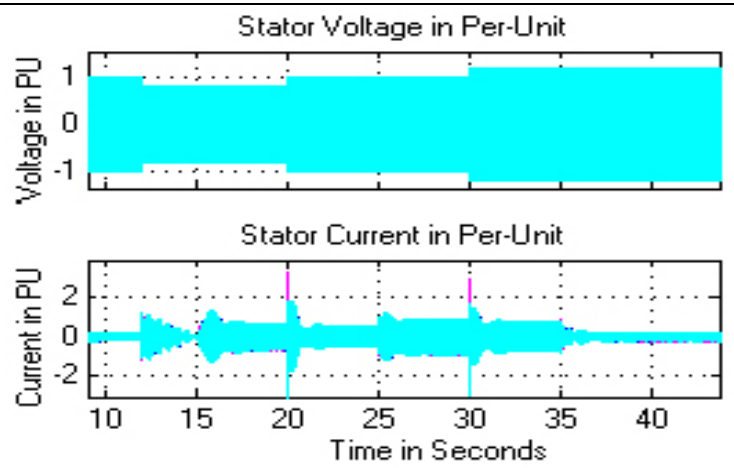

c (ii)

Figure 5c. Stator voltage and current three phase waveform with time for (i) reactive power change $\&$ wind speed variation, (ii) both grid voltage $\&$ wind speed changes

With sudden decrease in grid terminal voltage from $1 \mathrm{pu}$ to $0.8 \mathrm{pu}$ volts at 12 seconds, slowly stator current decreased exponentially when wind speed is very low of $0.1 \mathrm{pu}$ amps at $8 \mathrm{~m} / \mathrm{s}$ and this current was improved to $1 \mathrm{pu}$ when wind speed increased to $15 \mathrm{~m} / \mathrm{s}$. But when terminal voltage changed to $1 \mathrm{pu}$ from $0.8 \mathrm{pu}$ at $20 \mathrm{~s}$, current again reached to normal value of $0.5 \mathrm{pu}$ amps as in case 1 and the current increased to again $1 \mathrm{pu}$ when wind speed reaches $20 \mathrm{~m} / \mathrm{s}$. when the grid terminal voltage increased to $1.2 \mathrm{pu}$ from $1 \mathrm{pu}$, the stator current again decreased to $0.8 \mathrm{pu}$ amps and when wind speed finally reaches $10 \mathrm{~m} / \mathrm{s}$ with voltage at $1.2 \mathrm{pu}$, the current is $0.2 \mathrm{pu}$ Amps as in Figure 5c (ii). Hence with increase in voltage at constant wind speed, current decreases and with increase in wind speed at same voltage current will increase and vice-versa. In the similar way as does in stator voltage and current, rotor voltage and current will also vary, but rotor current is bidirectional unlike stator current does.

In these two cases, rotor voltage is nearly constant at $0.32 \mathrm{pu}$, but current is varying with both wind speed and reactive power change in Figure $5 \mathrm{~d}$ (i) and for voltage and wind speed variation as in Figure 5d (ii). When reactive power at $-0.6 \mathrm{pu}$, rotor current is $0.8 \mathrm{pu}$ is even low at $8 \mathrm{~m} / \mathrm{s}$ wind speed and increased to $1 \mathrm{pu}$ amps when wind speed reaches $15 \mathrm{~m} / \mathrm{s}$ as in Fig. $5 \mathrm{~d}$ (i). When reactive power reaches $1 \mathrm{pu}$, rotor current is $0.5 \mathrm{pu}$ amps at wind speed of $15 \mathrm{~m} / \mathrm{s}$ and for leading reactive power of $+0.6 \mathrm{pu}$, the rotor current is again $1 \mathrm{pu}$ at wind speed of $20 \mathrm{~m} / \mathrm{s}$ and $0.5 \mathrm{pu}$ amps at $10 \mathrm{~m} / \mathrm{s}$ wind speed. With increase in wind speed or at leading or lagging reactive power, rotor current is also increasing like stator current. In the same scenario, rotor current is decreasing with increase in grid terminal voltage and vice-versa but without any appreciable change in rotor voltage. With sudden changes in voltage at 12, 20 and 30 seconds, there are few spikes in rotor current due to sudden reversal of current magnitude and angle with respect to terminal voltages respectively.
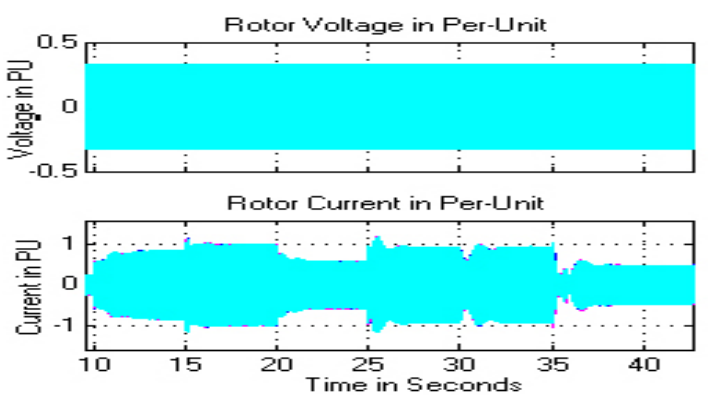

d (i)
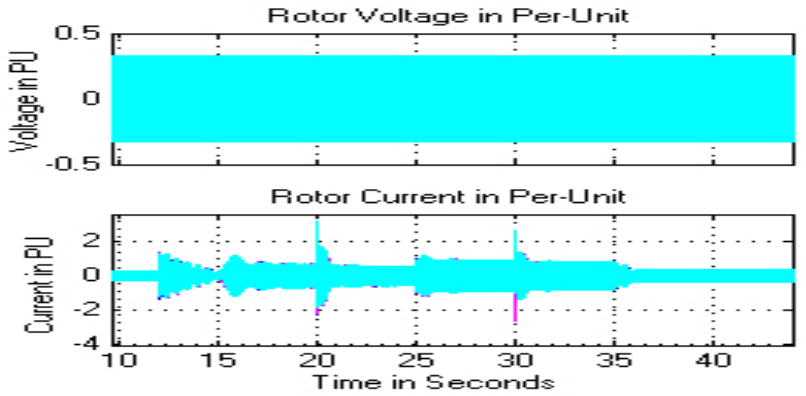

d(ii)

Figure 5d. Rotor voltage and current three phase waveform with time for (i) reactive power change $\&$ wind speed variation, (ii) both grid voltage $\&$ wind speed changes

The stator real and reactive power flow for all three cases is shown in Figure 5d. The reference power which is the mechanical power output from turbine and actual generator real power change is shown in Figure 5e. With change in wind speed, with very low wind speed of $8 \mathrm{~m} / \mathrm{s}$, output stator real power is $0.1 \mathrm{pu}$ watts till 15 seconds. When wind speed reaches $15 \mathrm{~m} / \mathrm{s}$, stator real power increased to $0.5 \mathrm{pu}$ and further increased to $0.8 \mathrm{pu}$ for $20 \mathrm{~m} / \mathrm{s}$ wind speed at $25 \mathrm{~s}$ and decreased to $0.2 \mathrm{pu}$ power at $35 \mathrm{~s}$ for $10 \mathrm{~m} / \mathrm{s}$ speed as

\footnotetext{
Tip Speed Ratio Based MPPT Algorithm and Improved Field Oriented Control for .... (D. V. N. Ananth)
} 
shown in Figure 6g (i). During the change in wind speed, real power alone is changing and reactive power is constant at reference of $0 \mathrm{pu}$. There are few surges in the reactive power due to change in voltage angle with respect to grid and also mainly due to change in stator and rotor current flows and rotor voltage change. With the change in reactive power demand from grid from $0 \mathrm{pu}$ to $-0.6 \mathrm{pu}$ and $+0.6 \mathrm{pu}$ at 12 and 30 seconds are shown in Figure 5d (i). With change in reactive power from $0 \mathrm{pu}$ to $-0.6 \mathrm{pu}$, reactive power from generator is changing with a small time lag of $0.8 \mathrm{~s}$ and real power maintained nearly constant value of $0.1 \mathrm{pu}$ at $8 \mathrm{~m} / \mathrm{s}$ wind speed. Similarly with reactive power changing to $0 \mathrm{pu}$ and $+0.6 \mathrm{pu}$, the reactive power is changing within 1 second and real power is almost constant with small surges in real stator power during this transient. In case with both voltage and wind speed changing, with the grid voltage variation from 1 to $0.8 \mathrm{pu}$ at 12 th second, real power which is at $0.1 \mathrm{pu}$ changed to $0.05 \mathrm{pu}$ and reactive power which is at $0 \mathrm{pu}$ reached $1 \mathrm{pu}$ at this 12 th second instant and slowly decaying to reach to reference 0 pu value as shown in Figure $5 \mathrm{~d}$ (ii). This change in reactive power is to make voltage of stator to get adjusted to grid voltage without losing synchronism.

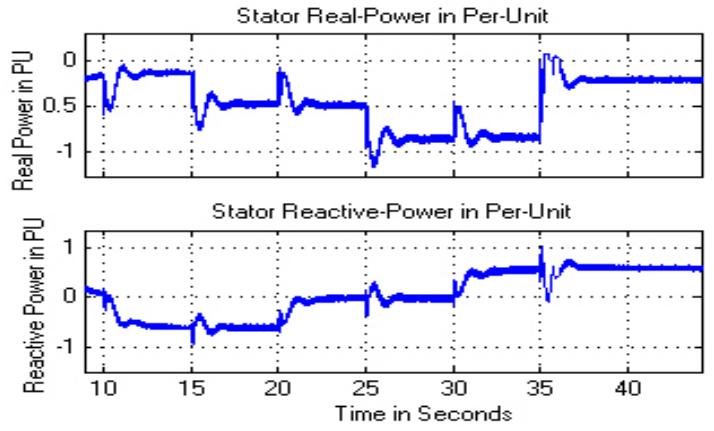

e (i)
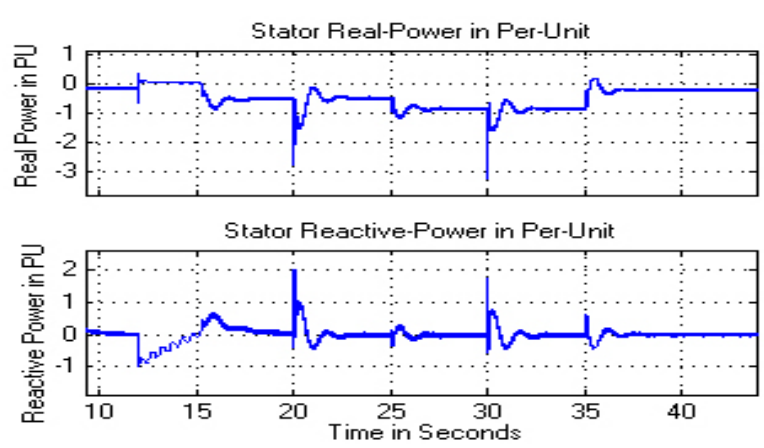

e (ii)

Figure 5e. Stator real and reactive power waveform with time for (i) reactive power change $\&$ wind speed variation, (ii) both grid voltage \& wind speed changes

The reference mechanical power output and generator actual power is matching with reference power and the mismatch is because of looses in turbine, gear wheels and generator and this mismatch is inevitable. With increase in wind speed, reference power is increasing and vice versa. With the change in voltage at grid, stator terminal real power is maintained at constant value but with surges at instant of transient but reactive power is adjusting till stator voltage reaches the grid voltage for maintaining synchronism as shown in Figure 5d (ii) and 5e (ii). At the instant of 20s and 30s, there is surge in real and reactive powers but were maintaining constant stator output real powers of 0.5 and $0.8 \mathrm{pu}$ watts and $0 \mathrm{pu}$ var as in Figure 5d (ii).
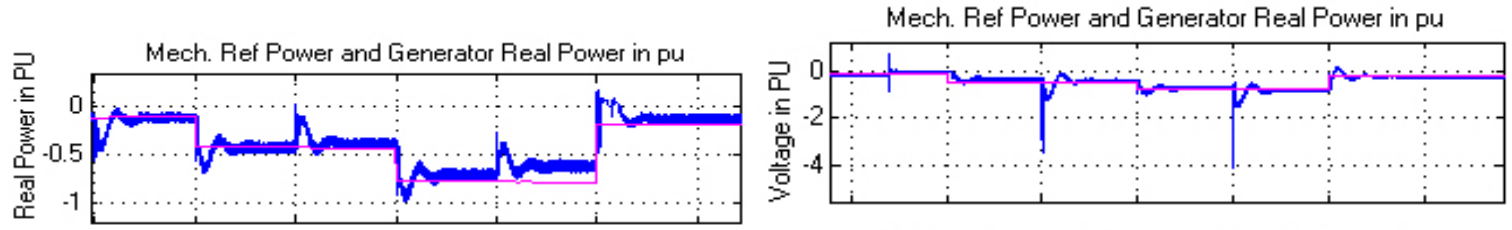

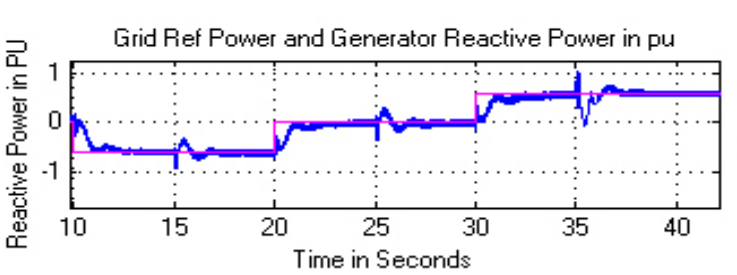

f(i)

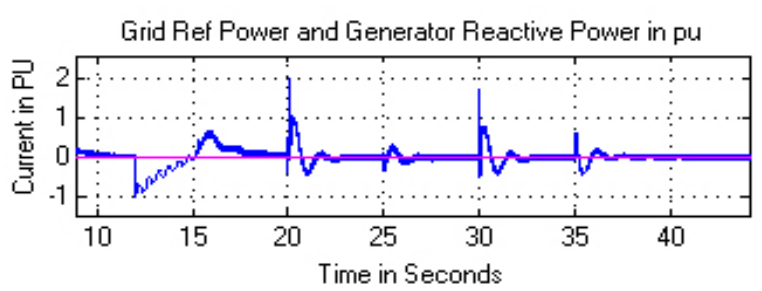

f (ii)

Figure 5f. generator reference and actual real power waveform with time for (i) reactive power change \& wind speed variation, (ii) both grid voltage $\&$ wind speed changes 
To meet the desired grid reactive power, both stator and rotor has to supply for faster dynamics with an aid to RSC and GSC control schemes and is achieving as shown in Figure $5 \mathrm{f}$ (i). With the change in wind speed and reactive power, real power from generator is matching its reference value for case 1 , but small deviation can be observed from time 30 to 35 seconds is due to sudden change in reactive power demand from grid and the deviation in real power is from $0.8 \mathrm{pu}$ to $0.7 \mathrm{pu}$ which is small. However, reactive power is following its trajectory within 1 second. In the case 2 in Figure $5 \mathrm{f}$ (ii), both voltage and reactive power changing with time, total output real and reactive powers from stator and rotor is delivering to grid to meet the desired grid power demand. Unlike with change in reactive power, change in voltage is not affecting any deviation in real power and is following the trajectory nearly accurate with maximum deviation of $5 \%$ in real power. The reactive power change with grid voltage is high when voltage decreased from $1 \mathrm{pu}$ to $0.8 \mathrm{pu}$ volts.

In the work in [17] by authors, the wind speed is changing gradually and real and reactive powers are changing rapidly. In our work, the wind speed is varying rapidly and according to changes in wind speed, the real power and current from stator are changing. Compared to the work in the reference [18], with much change in wind speed conditions, the real power, stator current and power are varying. The variations are much more precise and also the rotor speed in our case is nearly constant based on speed reference adjustment by MPPT algorithm. The rotor speed is adjusted to optimal value by using fast acting gear mechanism. Reactive power control in [19] is compared with PI, ANN and combination of both called as hybrid and authors proved that hybrid is better than individual operation with PI or ANN. With the proposed methodology, the reactive power can reach the standards of hybrid controller with PI controller. There are no surges in reactive power output or in current and voltage waveforms at grid or at DFIG a sin [19]. Similar to the work in [21], with the change in polarity of real power from positive to negative, the proposed method is also varying in the same way. There is also nearly same action of independent control over real and reactive power outputs from DFIG. Hence our work can perform better than the works presented in the earlier and can be valid for independent control of real and reactive power, and during rapid changing wind conditions. Also extraction of reference power from turbine using MPPT and tracking the same from the generator is also possible with the proposed methodology. The surges during any grid disturbances or due to wind speed conditions, the performance of DFIG system with proposed methodology is very accurate and stable.

\section{CONCLUSION}

From the proposed control scheme, the torque, speed and reactive power control of DFIG is very specific. With change in wind speed, electromagnetic torque surges are low and the variation in wind speed is not getting the generator rotor speed variation is due to better transition in gear wheel mechanism. Reactive power demand from grid is accurate which can be met by proper control action of RSC and GSC. The proposed methodology is accurate and following all basic mathematical equations explained in previous section. When wind speed is increasing, mechanical and electrical torques are increasing without any change in stator reactive power. Variation in grid reactive power causes quadrature currents on both stator and rotor to change but torque, speed or real powers from stator or rotor remains unaltered.

The variation in grid terminal voltage, a very small change in TSR and Cp can be observed. It is due to the fact that the TSR and Cp depends on parameters and is independent on voltage and reactive power. The TSR and $\mathrm{Cp}$ are blade size and shape with change in ambient temperature and wind speed dependant natural parameters. With increase in voltage at constant wind speed, current decreases but, with increase in wind speed at same voltage, current will increase and the decrease in wind speed caused current from stator to rotor decreases with stator voltage as constant as depicted by grid. In the similar way as does in stator voltage and current, rotor voltage and current will also vary, but rotor current is bi-directional unlike stator current does.

With the proposed control scheme, maximum power is captured from wind by DFIG even during light load conditions i.e. cut-in wind speed. This is attained by tracking optimal tip-speed ratio by controlling the DFIG electromagnetic torque during low and at rated wind speed. Further generator speed is maintained at optimal value by using look-up table by using the generated torque and thus the DFIG rotor current is controlled. Thereby maximum power is extracted from the turbine-generator set. Under full load condition i.e. when wind speed high, normally $24 \mathrm{~m} / \mathrm{s}$, maximum output power can be extracted if rotor is driven at optimal speed for that particular wind speed. If rotor speed can be referred to maintain at specified value, during wind speed variations, the rotor speed varies and gets adjusted. Independent and faster reactive power control from $+1 \mathrm{pu}$ to $-1 \mathrm{pu}$ without deviation in real power from DFIG is achieved with proposed RSC and GSC improved field oriented control techniques. The actual mechanical power output from turbine is matching with the real power production from DFIG is possible with MPPT and RSC control schemes.

The change in voltage at grid, stator terminal real power is maintained at constant value but with surges at instant of transient but reactive power is adjusting till stator voltage reaches the grid voltage for

Tip Speed Ratio Based MPPT Algorithm and Improved Field Oriented Control for .... (D. V. N. Ananth) 
maintaining synchronism. To meet the desired grid reactive power, both stator and rotor has to supply for faster dynamics and it depends on faster action of RSC and GSC control schemes. Distinct from reactive power variation, change in voltage is not affecting any deviation in real power and is following the trajectory nearly accurate with maximum deviation of $5 \%$ in real power. The reactive power change with grid voltage is high when voltage decreased from $1 \mathrm{pu}$ to $0.8 \mathrm{pu}$ volts. Hence the proposed control scheme can be applied with ever changing transients like large variation in wind speed, reactive power and grid voltage. The system is very stable without losing synchronism when grid voltage is increasing or decreasing to a \pm 0.2 pu change from nominal voltage value.

\section{APPENDIX}

The parameters of DFIG used in simulation are,

Rated Power $=1.5 \mathrm{MW}$, Rated Voltage $=690 \mathrm{~V}$, Stator Resistance Rs $=0.0049 \mathrm{pu}$, rotor Resistance $\mathrm{Rrl}=0.0049 \mathrm{pu}$, Stator Leakage Inductance Lls $=0.093 \mathrm{pu}$, Rotor Leakage inductance Llr $1=0.1 \mathrm{pu}$, Inertia constant $=4.54 \mathrm{pu}$, Number of poles $=4$, Mutual Inductance Lm $=3.39 \mathrm{pu}$, DC link Voltage $=415 \mathrm{~V}$, Dc link capacitance $=0.2 \mathrm{~F}$, Wind speed $=14 \mathrm{~m} / \mathrm{sec}$. Grid Voltage $=25 \mathrm{KV}$, Grid frequency $=60 \mathrm{~Hz}$. Grid side Filter: $\mathrm{Rfg}=0.3 \Omega, \mathrm{Lfg}=0.6 \mathrm{nH}$. Rotor side filter: $\mathrm{Rfr}=0.3 \mathrm{~m} \Omega, \mathrm{Lfr}=0.6 \mathrm{nH}$, Wind speed variations: $8,15,20$ and 10 at 15, 25 and 35 seconds. Reactive power change: -0.6 to 0 and $+0.6 \mathrm{pu}$ at 20 and 30 seconds. Grid voltage change: 0.8 to 1 and to $1.2 \mathrm{pu}$ at 20 and 30 seconds.

\section{REFERENCES}

[1] B. Shen, et al., "Sensorless Maximum Power Point Tracking of Wind by DFIG Using Rotor Position Phase Lock Loop (PLL)," IEEE Trans. Power Electron., vol/issue: 24(4), pp. 942-951, 2009.

[2] H. Li and Z. Chen, "Overview of different wind generator systems and their comparisons," Renewable Power Generation, IET, vol/issue: 2(2), pp. 123-138, 2008.

[3] Xu L. and Cartwright P., "Direct active and reactive power control of DFIG for wind energy generation," IEEE Trans Energy Convers, vol//issue: 21(3), pp. 750-8, 2006.

[4] M. Tazil, et al., "Three-phase doubly fed induction generators: an overview," Electric Power Applications, IET, vol/issue: 4(2), pp. 75-89, 2010.

[5] B. Singh, et al., "Performance of Wind Energy Conversion System Using a Doubly Fed Induction Generator for Maximum Power Point Tracking," in Industry Applications Society Annual Meeting (IAS), 2010 IEEE, pp. 1-7, 2010.

[6] E. Tremblay, et al., "Comparative Study of Control Strategies for the Doubly Fed Induction Generator in Wind Energy Conversion Systems: A DSP-Based Implementation Approach,” IEEE Transactions on Sustainable Energy, vol/issue: 2(3), pp. 288-299, 2011.

[7] Malinowski M., et al., "Virtual-flux-based direct power control of three-phase PWM rectifiers," IEEE Trans Ind Appl., vol/issue: 37(4), pp.1019-1027, 2001.

[8] A. M. Eltamaly and H. M. Farh, "Maximum power extraction from wind energy system based on fuzzy logic control," Elec. Pow. Sys. Research, vol/issue: 97(1), pp.144-150, 2013.

[9] Abdullah M. A., et al., "A review of maximum power point tracking algorithms for wind energy systems," Renew Sustain Energy Rev, vol/issue: 6(5), pp. 3220-3227, 2012.

[10] Raza K. S. M., et al., "Review and critical analysis of the research papers published till date on maximum power point tracking in wind energy conversion system," IEEE Energy Convers Congr Exposition, pp. 4075-82, 2010.

[11] Kazmi S. M. R, et al., "A novel algorithm for fast and efficient speed-sensorless maximum power point tracking in wind energy conversion systems," IEEE Trans Ind Electron., vol/issue: 58(1), pp.29-36, 2011.

[12] Koutroulis E. and Kalaitzakis K. "Design of a maximum power tracking system for wind-energy-conversion applications," IEEE Trans Ind Electron, vol/issue: 53(2), pp. 486-494, 2006.

[13] Cardenas R. and Pena R. "Sensorless vector control of induction machines for variable-speed wind energy applications," IEEE Trans Energy Convers, vol/issue: 19(1), pp.196-205, 2004.

[14] Datta R. and Ranganathan V. T., "A method of tracking the peak power points for a variable speed wind energy conversion system," IEEE Trans Energy Convers, vol/issue: 18(1), pp.163-168, 2003.

[15] Maurizio C. and Marcello P. "Growing neural gas (GNG)-based maximum power point tracking for highperformance wind generator with an induction machine," IEEE Trans Ind Appl., vol/issue: 47(2), pp.861-72, 2011.

[16] Morimoto S., et al., "Sensorless output maximization control for variable-speed wind generation system using IPMSG," IEEE Trans Ind Appl., vol/issue: 41(1), pp. 60-7, 2005.

[17] K. Murthy, et al., "A performance comparison of DFIG using power transfer matrix and direct power control techniques," International Journal of Power Electronics and Drive Systems (IJPEDS), vol/issue: 5(2), pp.176-184, 2014.

[18] Z. Nora and L. Hocine, “Active and Reactive Power Control of a Doubly Fed Induction Generator," International Journal of Power Electronics and Drive Systems (IJPEDS), vol/issue: 5(2), pp. 244-251, 2014. 
[19] V. M. Gopala and Y. P. Obulesu, "A New Hybrid Artificial Neural Network Based Control of Doubly Fed Induction Generator," International Journal of Electrical and Computer Engineering (IJECE), vol/issue: 5(3), 2015.

[20] G. V. Madhav and Y. P. Obulesu, "A Fuzzy Logic Control Strategy for Doubly Fed Induction Generator for Improved Performance under Faulty Operating Conditions," International Journal of Power Electronics and Drive Systems (IJPEDS), vol/issue: 4(4), pp. 419-429, 2014.

[21] A. Boulahia, et al., "Predictive Power Control of Grid and Rotor Side converters in Doubly Fed Induction Generators Based Wind Turbine," Bulletin of Electrical Engineering and Informatics, vol/issue: 2(4), pp. 258-264, 2013.

[22] K. L. Sireesha and G. K. Rao, "Droop Characteristics of Doubly Fed Induction Generator Energy Storage Systems within Micro Grids," International Journal of Power Electronics and Drive Systems (IJPEDS), vol/issue: 6(3), pp. 429-432, 2015.

\section{BIOGRAPHIES OF AUTHORS}

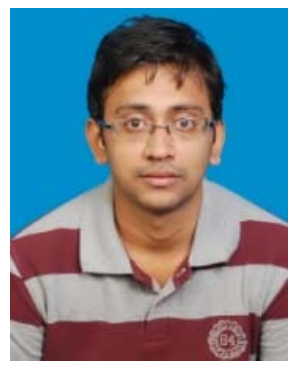

D.V.N. Ananth was born in Visakhapatnam, India on 20th August 1984. He received B.Tech Electrical Engineering from Raghu Engineering College, Visakhapatnam and M.Tech from Sreenidhi Institute of Science \& Technology, Hyderabad, India. He is working as an Assistant Professor in VITAM College of Engineering in Electrical Department since December 2010. $\mathrm{He}$ is currently working towards his $\mathrm{PhD}$ degree from GITAM University, Visakhapatnam His favorite topics include Renewable energy resources, DFIG, industrial drives, power systems, power electronics, control systems, HVDC and Reactive power compensation techniques. His contact address is nagaananth@gmail.com

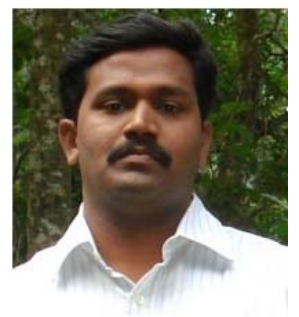

Dr. G.V. Nagesh Kumar was born in Visakhapatnam, India in 1977. He graduated College of Engineering, Gandhi Institute of Technology and Management, Visakhapatnam, India, Masters Degree from the College of Engineering, Andhra University, Visakhapatnam. He received his Doctoral degree from Jawaharlal Nehru Technological University, Hyderabad. He is presently working as Associate Professor in the Department of Electrical and Electronics Engineering, GITAM University, Visakhapatnam. His researches interests include gas insulated substations, fuzzy logic and neural network applications, distributed generation, Partial Discharge Studies and Bearingless drives. He has published 102 research papers in national and international conferences and journals. He received "Sastra Award", "Best Paper Award" and "Best Researcher Award". He is a member of various societies, ISTE, IEEE, IE and System Society of India. He is also a reviewer for IEEE Transactions on Dielectrics and Electrical Insulation, Power Systems and a member on Board of several conferences and journals. 